\title{
PREDICTION OF WOVEN FABRIC PROPERTIES USING SOFTWARE PROTKATEX
}

\author{
Brigita Kolčavová Sirková, Iva Mertová
}

Technical University of Liberec, Faculty of Textile Engineering, Department of Textile Technologies, Liberec, Czech Republic

Studentská 2, 46117 Liberec 1

E-mail: brigita.kolcavova@tul.cz, iva.mertova@tul.cz

\begin{abstract}
:
Fabric properties and fabric structure prediction are important in each industry domain. Generally all professional $C A D$ packages for woven textiles system will be able to achieve basic fabric simulation and production output. $A$ good CAD system should enable you to create design (dobby and jacquard woven fabric) ideas quickly and easily to enhance the way you work. The differences among competing systems fall mainly into the following categories: ease of use; speed of operation; flexibility of operation; advanced features; technical support; and ongoing software development. Computer simulation or prediction is oriented on standard woven fabrics, technical textiles, and composites. This article focuses on the presentation of software ProTkaTex and its use in the prediction of woven fabric properties. The software implements a generalized description of the internal structure of woven fabric on the unit cell level, integrated with mathematical models of the fabric relaxed state. User can calculate selected mechanical and end-use properties of dobby and jacquard woven fabric as well as can evaluate fabric behavior before real weaving. The major challenge is to develop software that industry will use in design centers for creation and development of new fabric structures for technical as well as clothing application.
\end{abstract}

\section{Keywords:}

Fabric geometry, weave, warp, weft, property, simulation, prediction

\section{Introduction}

Computer-aided design (CAD) is the use of computer technology for the process of design and design documentation. CAD software, or environments, provides the user with input-tools for the purpose of streamlining design processes, i.e. drafting, documentation, and manufacturing processes. CAD output is often in the form of electronic files for print or manufacturing.

CAD environments often involve more than just shapes. As in the manual drafting of technical and engineering drawings, the output of CAD must convey information, such as materials, processes, dimensions, and tolerances, according to application-specific conventions. CAD is an important industrial art extensively used in many applications, including automotive, shipbuilding, and aerospace industries, industrial, textile and architectural design, prosthetics, and much more. CAD is also widely used to produce computer animation for special effects in movies, advertising, and technical manuals [1]. All professional CAD packages for woven textiles will be able to achieve basic fabric simulation and production output. The difference among competing systems falls mainly into the following categories: ease of use, speed of operation, flexibility of operation, advanced features, technical support, and ongoing software development [12-15]. These systems are compatible with electronic dobby or jacquard shedding mechanism; production data can be sent directly to electronic loom controllers.

A good CAD system should enable you to create design ideas quickly and easily to enhance the way you already work.
It should be able to fit seamlessly into your current working practices and become a valuable timesaving, creative tool that works with you [14].

CAD systems support the creation of everything, from simple single cloth structures to complex layered architectures, containing stacking orders and variable densities as well as $2 \mathrm{D}$ and $3 D$ visualization of fabrics. 3D simulation module creates fabric visualization on the basis of 3D weave, yarn thickness, warp and weft density. Warp and weft parameters may be set and displayed individually. Separate layers can be isolated and edited on its own, or the whole fabric can be viewed and manipulated as a whole [12].

\section{CAD systems for prediction of fabric properties}

The aim of CAD system for fabric properties prediction is to optimize the construction of textiles on the basis of virtually created fabrics [20]. Prediction of fabric properties is based on a combination of mathematical modeling and experimental research, including development and application of nonstandard methods for definition and measuring of the fabric structure [16,19,22,24]. Mathematical models are possible to use for modeling the geometry of textile structures as well as properties, including textile mechanics, permeability, drape, roughness, and composite mechanical behavior [24-27].

At present, the software packages implement a generalized description of the internal structure of textile reinforcements on the unit cell level, integrated with mechanical models of 
the relaxed and deformed state of 2D- and 3D-woven (see Figure 1), two- and three-axial braided, weft-knitted and non-crimp warp-knit stitched fabrics $[16,18,38]$. Realistic models have application in the design and manufacture of textile composites. A composite material is one that is made by combining two existing materials: in a fiber-reinforced composite, stiff, strong fibers form one part of the composite, reinforcing the other. In manufacturing, it is common for this reinforcing material to be supplied in textile form, woven from 'yarns' made from the fibers $[22,23]$.

Some modules of CAD system are focused on simulation of 3D-woven fabrics with consideration of weaving technological boundary conditions: quick check up of the feasibility of geometry from 3D-woven fabrics; prediction of woven 3D structure and quality for each position of geometry; optimization of parameters of the 3D-woven fabric (thread sizes, weave, and thread distances) by simulation [19]. The packages are dedicated for the design and manufacture (CAD/CAM) of advanced textile structures based on the use of conventional weaving technology. It has been used for the design and manufacture of 3D textile structures, with both solid and hollow architectures, and non-crimp composite reinforcement [22,23] Software packages can be used for the prediction of standard gray fabric properties for technical and clothing applications. In this case, the software can predict selected properties and fiber parameters in module fiber, selected yarn properties and parameters in module yarn, selected fabric properties and parameters in fabric module. The system contains databases of fiber properties and fabric weaves, and the prediction is based on the complex of theoretical and regression models. The material and technological parameters for different materials, yarns and fabrics are included. The system is mainly used for the optimization of fabric design based on virtually created fabric [20].

\section{Prediction of woven fabric properties: software Protkatex}

ProTkaTex software can be applied for the prediction of selected mechanical and end-use woven jacquard fabric properties with knowledge of the yarns' properties and fabric interlacing. ProTkaTex was developed at the Faculty of Textile Engineering, Technical University of Liberec. The software is compatible with common CAD jacquard and dobby weaving design systems. ProTkaTex enables $3 \mathrm{D}$ visualization of fabrics based on the input yarn parameters. It is used for properties, prediction on the basis of combination of mathematical modeling and experimental research [2,4,31]. The major challenge is to develop a software package that industry will use in design centers for the creation and development of new fabric structures for technical as well as clothing application.

In comparison with the above-mentioned software packages, this software is focused on the determination of standard dobby fabrics as well as jacquard fabrics, and is not focused on the description of textile composite. At this stage, the weave (small and big patterns) covers the structure of single-layer woven fabrics. It is able to evaluate the jacquard pattern with unlimited number of warp and weft threads. On the basis of definition and evaluation of individual interlacing pores in repeat defines the fabric structure and distribution of interlacing points, which influence mechanical and end-use properties. The software consists of three modules: yarn definition, fabric properties, and weaves (design). For the prediction of selected woven fabric properties, it is necessary to know basic input yarn properties. Warp and weft threads are defined on the basis of: type of yarn, fiber packing density $\mu$ [], yarn count $T$ [tex], specific density $r\left[\mathrm{~kg} / \mathrm{m}^{3}\right]$, yarn strength Fpr [N or N/tex], yarn elongation Epr [\%], and yarn irregularity CV [\%]. Definition of fiber packing density: inside of the textile fibrous assembly or inside of some spatial part of them, there lies fiber volume $V$. Total volume of this body is called $V c$. The compactness of this body is characterized by the ratio between these two volumes and is known as fiber packing density. (Note: alternatively, this value is called the packing ratio or volume fraction.) Evidently, the fiber packing density value must lie in the interval from 0 to 1 [4]. Type of yarn is evaluated by technology as well as yarn structure (staple yarn, multifilament yarn, etc.). Software ProTkaTex distinguishes the technologies: combed, carded, and open-end. Based on experimental and theoretical research work $[4,32,35]$, different types of yarn were analyzed (on the basis of threads cross-section evaluation, see Figures 2 and 3 ) and their construction parameters, and mathematical equations were prepared for yarn parameters prediction. Theoretical expressions of individual parameters of yarn (fiber packing densities, compression of yarn in relaxing state before weaving as well as in fabric, diameter of threads) were compared with experimental parameters that followed from real cross-section of yarn and woven fabric [5-7].

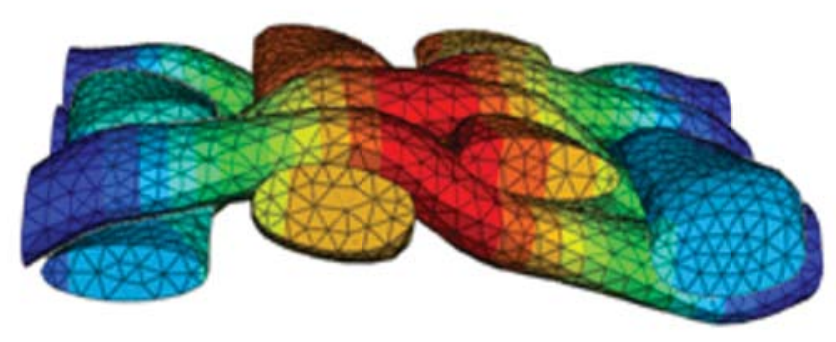

Figure 1. Modeled deformed twill weave unit cell in tension [17].
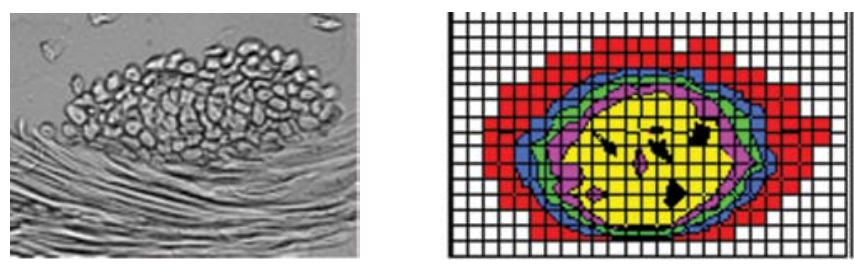

Figure 2. Definition of yarn diameter in cross-section.

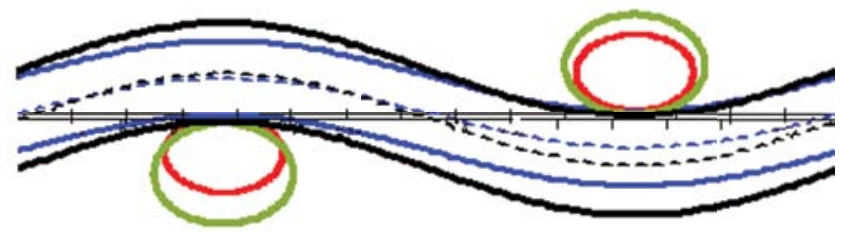

Figure 3. Modeling of cross-section in fabric. 


\section{Weave definition and prediction of woven fabric properties}

Woven fabric weave determines the manner of the thread's interlacing in the fabric [2]. Definition of individual pores in weave - expression of pores frequency in weave (in rows and in columns) - is used for description of threads interlacing by mathematical equation in this software. In the woven fabric weave, exists only four structural models of interlacing [33], see Figure 4. Dobby as well as jacquard pattern is possible to create by various combinations of these structural pores in repeat. Jacquard design is not possible to create in ProTkaTex. The software is compatible with CAD jacquard design systems (EAT, NedGraphics, Arachne, ScotWeave, etc.), where pattern has to be saved in one of the following formats: TIFF, BMP, JPEG (see Figure 5).

Jacquard weave in the above-mentioned format (see Figure 6) can be opened in module "weave" and then converted into a format required for fabric properties prediction in ProTkaTex. This software uses its own format, VZB.

Description of woven fabric properties and parameters is based on the complex of theoretical and regression models. Prediction is based on the knowledge of yarn parameters and interlacing of individual threads in dobby and jacquard pattern. Calculation of individual fabric properties and mathematical formulations were created on the basis of analysis of areal and spatial fabric geometry. As mentioned above, the software calculates selected properties for dobby as well as jacquard woven fabric. It is possible to predict the following properties of fabrics: relative wave height $\square$ (separately for warp and weft system), warp and weft density [treads $/ 100 \mathrm{~mm}$ ], weight of fabric $\left[\mathrm{g} \cdot \mathrm{m}^{-2}\right.$ ], cover of fabric [\%] (separately for warp and weft system too), crimp of threads in fabric [\%] (warp and weft), fabric thickness [mm], fabric roughness [ $\mu \mathrm{m}]$, fabric strength [N/5cm] (for warp and weft direction), and fabric elongation [\%] (for warp and weft direction). For presentation of individual results of prediction, the abovementioned properties were selected. In the above-mentioned graphs we can see fabric properties behavior and comparison of theoretical values with experimental values. Parameters of fabric samples: All fabrics are in plain weave. Material composition: $100 \%$ PP yarn and $100 \%$ CO yarn in three counts 20 tex, 29,5 tex and 45 tex in both directions.

\section{Weight of fabric}

Calculation of weight of fabric in this software is based on the warp and weft sett and on the yarn count as well as yarn crimp [31]. The software distinguishes two kinds of fabric weight: weight of linear meter of fabric $\left[g^{\prime} \cdot \mathrm{bm}^{-1}\right]$ and weight of square meter of fabric $\left[g \cdot m^{-2}\right]$.

\section{Fabric thickness}

Fabric thickness is defined as perpendicular distance to the fabric, which determines the dimension between the upper and lower side of the fabric. Prediction of fabric thickness depends on fabric geometry description. Mathematical description is based on definition of binding wave in repeat and threads' waviness in interlacing [37]. Threads' deformation in interlacing
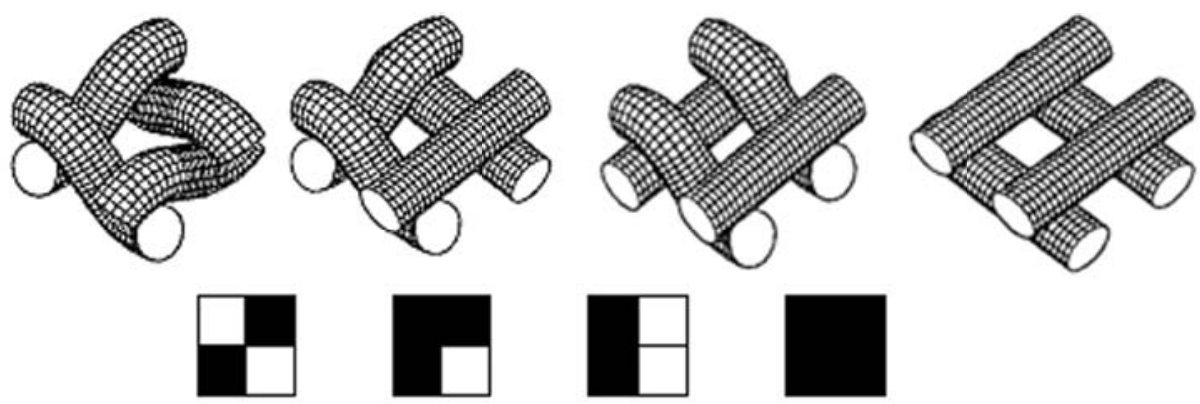

Figure 4. Principle of X-Ray Tomography.

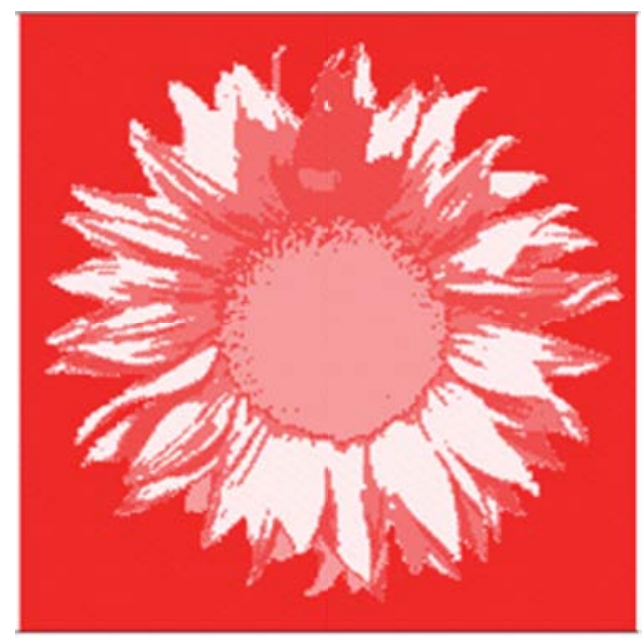

Figure 5. Principle of X-Ray Tomography.



Figure 6. Principle of X-Ray Tomography. 
is dependent on the yarn structure and fabric input parameters (weave, warp and weft waviness, warp and weft sett) $[4,33]$. In the following model (1), the main influence is from yarn diameter and weft and warp waviness.

$$
\text { thickness }[m]=\left[\left(d_{o}+d_{u}\right)+\left[\frac{d_{o}+d_{u}}{2} \cdot e \mathrm{l}-\frac{d_{o}+d_{u}}{2},(1-e \mathrm{l})\right] \mid\right] \cdot f^{m} \cdot \beta
$$

where $d_{0}$ - warp diameter, $d_{u}-$ weft diameter, e1 - warp waviness, $f^{m}$ - interlacing coefficient, $\beta$ - yarn compression in fabric (the yarn deformation in interlacing).

\section{Fabric elongation}

Prediction of fabric elongation in the warp and weft direction is defined as a fabric extension for maximum strength (the breakage) to the original length of fabric. Fabric elongation in warp and weft direction depends on yarn elongation and yarn interlacing in fabrics. Calculation of fabric elongation is based on definition of threads' crimp and level of threads' interlacing (which is necessary to evaluate the number of interlacing parts as well as float part in repeat [31]).

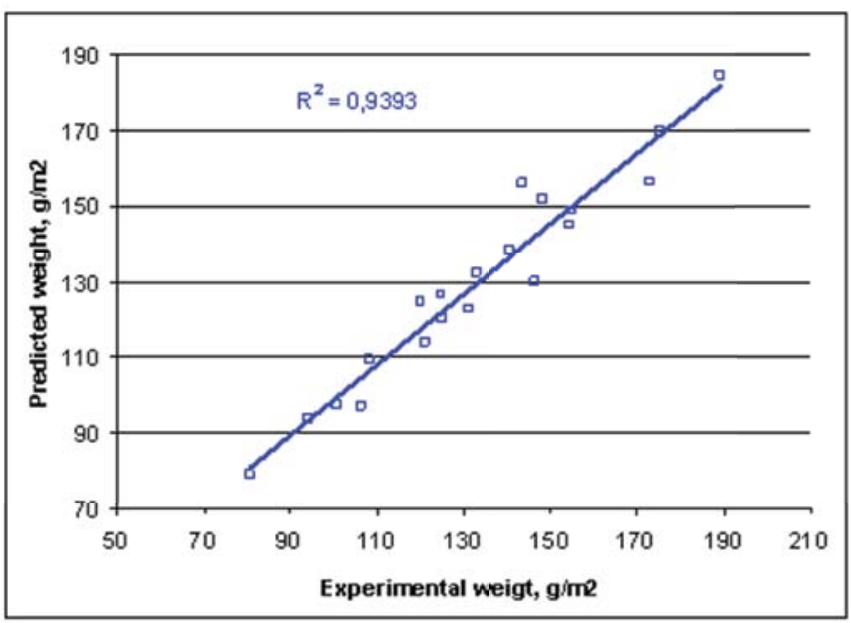

Figure 7. Principle of X-Ray Tomography.

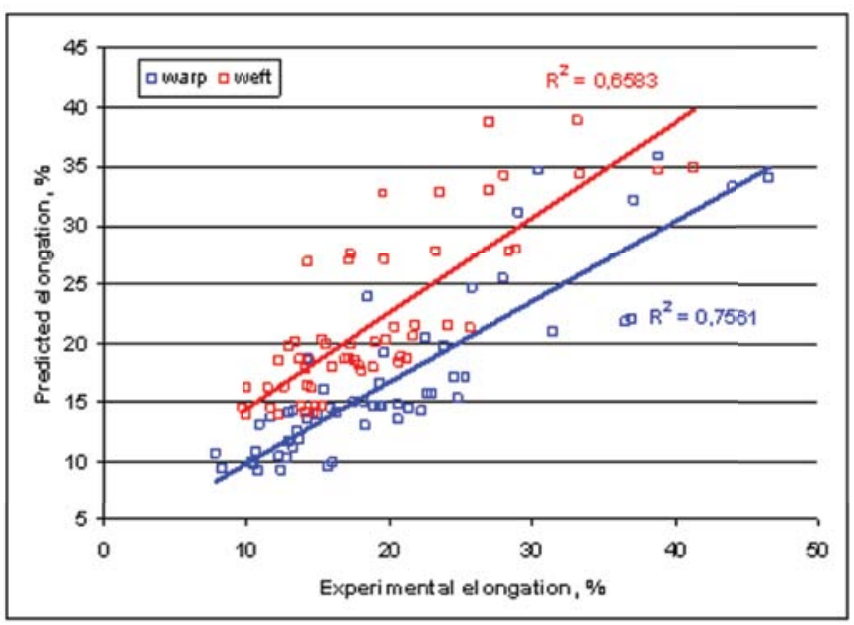

Figure 9. Principle of X-Ray Tomography.

\section{Fabric strength}

Prediction of fabric strength in warp or weft direction depends on warp (weft) yarns and warp (weft) sett. The influence of second system on fabric strength value is neglected. Woven fabric strength does not correspond to the sum of yarn's strength per fabric width unit in straining direction only. Relation between fabric and yarn strength is corrected by coefficient of utilization of yarn in fabric in warp (weft) direction. It is assumed that coefficient includes influence of material and fabric weave.

\section{Fabric roughness}

Roughness is a surface micro-geometry and is defined as the sum of unevenness (geometric deviations) of the surface with relatively small distances. It is an important parameter influencing subjective hand feeling and is connected with behavior of textiles' layers in mutual contact. Calculation of roughness is based on the definition of structural pores in repeat, fabric geometry description, threads' interlacing as well as yarn irregularity [37].



Figure 8. Principle of X-Ray Tomography.

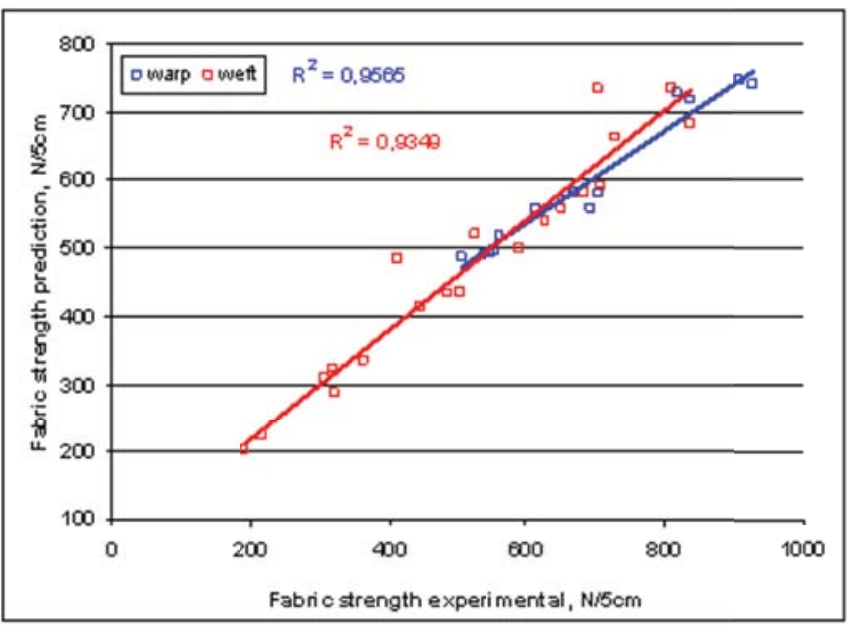

Figure 10. Principle of X-Ray Tomography. 


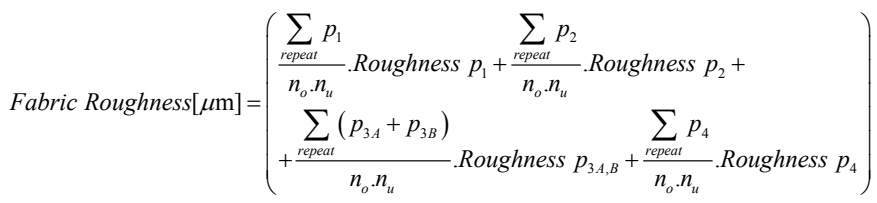

$$
\begin{aligned}
& \frac{100}{\frac{D_{o}+D_{u}}{2}} \cdot \frac{100}{100-C V} \cdot 10^{3}
\end{aligned}
$$

where $D_{\mathrm{u}, \mathrm{o}}$ [threads / 100mm] - weft, warp density, $p_{1-4}[]-$ pores in weave (definition of interlacing cell in repeat), CV [\%] - yarn irregularity.

\section{Conclusion}

The ProTkaTex software provides an integrated description of the internal geometry of dobby and jacquard fabric and their properties. It is one of the few software packages that are able to characterize and determine the behavior of complicated jacquard patterns in selected properties. The major challenge is to develop a software product that industry will use in design centers for the creation and development of new fabric structures for technical as well as clothing application.

At present are elaborated additional properties and their mathematical formulation that will be implemented in software and extend the existing possibilities of prediction. Software is open to be used in further developments of creation and prediction of new fabric structures and their properties.

\section{Acknowledgment}

This work was supported by the project Textile Research Centre $1 \mathrm{M} 0553$ and by the project GACR 106/09/1916.

\section{References}

[1] Vijay Duggal. "CADD Primer". Mailmax Publishing, http://www.caddprimer.com/cadd_primer_chapters/

[2] Nosek, S.: The structure and geometry of the woven fabrics, Liberec 1996,

[3] Behera, B.K., Hari, P.K.: Woven textile structure, Theory and applications, Woodhead Publishing Limited, ISBN 978-1-84569-514-9 (book), 2010

[4] Neckár̆, B.: Compression and Packing Density of Fibrous Assemblies. Textile Research Journal, pp. 123-130 Vol. 67 No. 3.

[5] Plívová, H., Influence of interlacing and sett of threads on the yarns shape in the weave for the cotton woven fabric - only in Czech, Diploma thesis Faculty of Textile Engineering, Technical University of Liberec 2001

[6] Nový O., Spectral analysis of binding waves in the woven fabric with carbon fibres, - only in Czech, Diploma thesis Faculty of Textile Engineering, Technical University of Liberec 2004

[7] Čaprnková N.: Analysis of the woven fabric cross-section produced from twisted yarns - only in Czech, Diploma thesis Faculty of Textile Engineering, Technical University of Liberec 2007

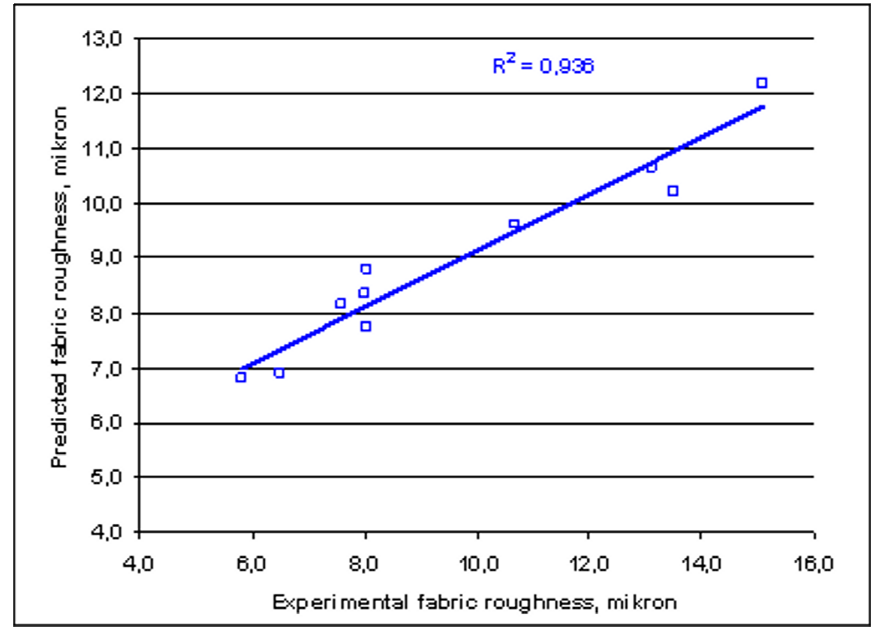

Figure 11. Principle of X-Ray Tomography.

[8] Kašparová K.: Design possibilities of woven jacquard fabric, Bachelor work, Faculty of Textile Engineering, Technical University of Liberec 2009

[9] Peirce, F.T.: The Geometry of Cloth Structure, Journal of Textile Institute, Vol.28, 1937

[10] Kemp, A. J.: Textile Institute 49, T44, 1958

[11] Duckett, K. E., Cheng C. C.: A Discussion of The Crosspoint Theories, Journal of the Textile Institute, Volume 69, Issue 2 \& 3 February 1978, pp. 55-59.

[12] CAD/CAM systems for weaving - ScotCad Textiles Limited, www.scotweave.com.

[13]CAD/CAM systems for weaving EAT www.designscopecompany.com.

[14]CAD/CAM systems for weaving -NedGraphics, www.nedgraphics.com.

[15] CAD /CAM systems for weaving - Arachne, www.arahne.si

[16]Lomov, S., Verpoest, I., Modelling of the internal structure and deformability of textile reinforcements: WiseTex software, In Proc. of 10th European Conf. Composite Materials (ECCM-10) (Brugge, Belgium, June 3--7, 2002)

[17] Lomov, S. V., G. Huysmans, and I. Verpoest: Hierarchy of Textile Structures and Architecture of Fabric Geometric Models, Textile Research Journal, Jun 2001; vol. 71

[18] Košek M., Mikolanda T., Košková B.: Ideal, Real and Virtual Textile Structure Modeling and Visualization, Afriograpf 2004, Proc. Of 3rd International conference on computer graphics, South Africa 2004

[19] CAD-Simulation of $3 D$ woven shapes, Department of Textile and Clothing Technology, Niederrhein University of Applied Sciences, Germany

[20] Křemenáková D., Kolčavová S. B., Mertová I.: Libtex software package, Technical University of Liberec, Textile Faculty, National research Center TEXTIL I, Czech Textile Seminar Greece May 2005

[21] Szosland J.,: Modelling the structural barrier ability of woven fabrics, Textile research, Department of Textile Architecture, Technical University of Łódź, Poland

[22] Hearle, J.W.S., Grosberg P., Backer, S.: Structural Mechanics of Fibers, Yarns, and Fabrics, (book) WileyInterscience 1969 
[23] Hearle, J.W.S.: Engineering design of textiles, Indian Journal of Fibre and Textile Research, Special Issue, 2005

[24] http://www.texeng.co.uk

[25] Long A.: TexGen - Open Source Software for Modelling of Technical Textiles, Transfer Summit/UK, Keble college, Oxford, 2011

[26] H. Lin, X. Zeng, M. Sherburn, A. C. Long and M. J. Clifford. "Automated geometric modelling of textile structures", Textile Research Journal, in press, May 2011

[27] http://texgen.sourceforge.net/index.php/Main_Page

[28] Masajtis, J.: Analiza strukturalna tkanin, Polska Akademia Nauk Oddzial w Łodzi, Komisja Włokiennictwa, Łodź 1999

[29] Barburski M., Masajtis J.; Modelling of the Change in Structure of Woven Fabric under Mechanical Loading. FIBRES \& TEXTILES in Eastern Europe, January/March 2009, Vol. 17, No. 1 (72) pp. 39-44.

[30] Szosland J., 'Kształtowanie własności tkanin poprzez kształtowanie fazy ich struktury' (in Polish, 'Designing of woven fabric features by designing the phase of their structure'), Architektura Tekstyliów, No. 1-3, 1999

[31] Keefe, M.: Solid Modeling Applied to Fibrous Assemblies PartIl: Woven Structure, Journal of Textile Institut, Vol.85 No.3, 1994 [350-358]

[32] S. Backer. The relationship between the structural geometry of textile and its physical properties, I: Literature review. Text. Res. J. 1948, 18: 650-658.
[33] Sirková, B.: Theses, Mathematical model for description of thread's interlacing in fabric using Fourier series, Liberec 2002

[34] Stepanović, J., Milutinović, Z., Petrović, V., Pavlović, M.: Influence of relative density on deformation characteristics of plain weave fabrics, Indian Journal of Fibre \& Textile Research Vol. 34, March 2009

[35] Milašius V.: Woven Fabric's Cross-Sec $\neg$ tion: Problems, Theory, and Experimental Data, Fibres and Textiles in Eastern Europe No 4(23)/98, pp. 48-50.

[36] Oloffson B.; „A general model of a fabric as a geometric mechanical structure" J. Textiles Isnt. Nr11,55, pp. 541557; 1964.

[37] Ozgen, B., Gong, H.: Yarn geometry in woven fabrice, Textile Research Journal, May 2011; vol. 81, 7: pp. 738745 ,

[38] Ozgen, B., Gong, H.: Modelling of yarn flattening in woven fabrice, Textile Research Journal, September 2011; vol. 81, 15: pp. 1523-1531.

[39] Kolčavová S. B.: Description of fabric thickness and roughness on the basis of fabric structure parameters, 18th International conference Strutex 2011, Liberec, Czech Republic 2011

[40] Kurashiki, T., H. Nakai, S. Hirosawa , M. Imura, M. Zako, S.V. Lomov, and I. Verpoest, Mechanical behaviors for textile composites by FEM based on damage mechanics, Key Engineering Materials, 2007, 334-335 (Advances in Composite Materials and Structures): 257-260. 